\title{
PROCESSOS DE INTERNACIONALIZAÇÃO E SEUS LEGADOS INVOLUNTÁRIOS: O CASO DA FORMAÇÃO DE PROFESSORES DE INGLÊS COMO LÍNGUA ADICIONAL DOS CENTROS DE LÍNGUA INGLESA DO PROGRAMA IDIOMAS SEM FRONTEIRAS
}

\author{
INTERNATIONALIZATION AND ITS INVOLUNTARY LEGACIES: TEACHER \\ DEVELOPMENT IN BRAZILIAN LANGUAGES WITHOUT BORDERS PROGRAM
}

\author{
William Kirsch ${ }^{1}$
}

\begin{abstract}
Resumo: Este trabalho faz uma breve revisão dos trabalhos de pesquisa dos últimos quatro anos que têm o programa Idiomas sem Fronteiras como principal objeto de investigação, quer seja o programa de modo global quer sejam experiências locais ocorridas nas universidades. Pode-se afirmar que o programa, inicialmente lançado como um programa acessório à internacionalização das universidades brasileiras e ao programa Ciências sem Fronteiras, tornou-se um programa de formação de professores, conforme revela uma análise bibliográfica das produções que serviram de corpus para o presente estudo. Isso se deu, conforme minha linha argumentativa, a partir do contexto de prática do programa para, depois, atingir o campo da formulação política; isto é, de modo bottom-up.
\end{abstract}

PALAVRAS-CHAVE: Idiomas sem Fronteiras - Políticas linguísticas - Formação de professores - Ciclo de Políticas

\begin{abstract}
This paper reviews the research reports that have focused on the program Languages without Borders over the past four years, both in more general terms and in the specific experiences that happen locally at universities. It is possible to affirm that the program, initially planned as an accessory to the internationalization of Brazilian universities and of the Science without Borders program, has become a program of teacher development, as the analysis of the productions used as corpus for this research reveals. This has happened, I argue, in the context of local practice to that of policy planning, that is, in a bottom-up direction.
\end{abstract}

KEYWORDS: Languages without Borders; Language policies; Teacher development; Policy cycle

\section{Introdução}

O Programa Ciência sem Fronteiras (CsF) foi um programa de intercâmbio acadêmico entre o Brasil e instituições de ensino de vários países ${ }^{2}$, que teve por finalidade promover a

\footnotetext{
${ }^{1}$ Doutor em Letras pela Universidade Federal do Rio Grande do Sul (2017).

${ }^{2}$ http://www.cienciasemfronteiras.gov. br/web/csf/paises, consultado 20/01/2014.
} 
consolidação, expansão e internacionalização da ciência e tecnologia, da inovação e da competitividade brasileira por meio do intercâmbio e da mobilidade internacional. A iniciativa foi fruto do esforço conjunto dos Ministérios da Ciência, Tecnologia e Inovação (MCTI) e do Ministério da Educação (MEC), por meio de suas respectivas instituições de fomento - CNPQ e CAPES -, e Secretarias de Ensino Superior e de Ensino Tecnológico do MEC. O objetivo primário do programa era, inicialmente, distribuir 101 mil bolsas até 2015, com uma verba de em torno de 3,5 bilhões de reais por meio de suas agências de fomento CAPES e CNPQ. O resultado, porém, ficou ligeiramente aquém disso - 93,249 bolsas entre pós-graduação e, sobretudo, graduação $(73,353)^{3}$.

As primeiras chamadas ocorreram em 2011 e 2012: Portugal obteve 40,317 candidaturas enquanto os Estados Unidos obtiveram 29,889. Podemos comparar os números de universidades em cada país para termos uma ideia da implicação de tal número de candidatura: 154 em Portugal $^{4}$ e 4,360 no Estados Unidos ${ }^{5}$. Em outras palavras, havia uma questão relativa à proficiência em línguas adicionais a ser endereçada.

A questão do conhecimento de língua adicional foi abordada por Glaucius Oliva, então presidente do $\mathrm{CNPq}$, que aconselhou os alunos de graduação a sempre aproveitarem as oportunidades de estudar "línguas estrangeiras" e de fazer cursos no exterior desde o seu primeiro dia de curso superior. Ele também afirmou em um dos vídeos de lançamento do IsF, que via a necessidade haver "uma avaliação da necessidade de língua que esse aluno venha a ter, ou seja, se ele vai precisar fazer um curso de idioma e de qual duração"

Em abril de 2013, Aloisio Mercadante, então no cargo de Ministro da Educação, declarou que as universidades portuguesas seriam excluídas do CSF para "estimular os alunos na proficiência de outras línguas. [já que] Eles têm que enfrentar o desafio da segunda língua" ${ }^{7}$. Naquele momento, o governo federal já havia organizado um grupo de trabalho chamado Inglês sem Fronteiras (IsF), com os seguintes objetivos: (1) avaliar a proficiência em inglês dos alunos das Instituições de Ensino Superior (IES), (2) oferecer cursos à distância e tutorias para esses cursos e (3) oferecer cursos presenciais a esses alunos.

\footnotetext{
${ }^{3}$ Kirsch e Sarmento (2018).

${ }^{4}$ http://www.universia.pt/universidades (consultado em 29/01/2019)

${ }^{5}$ https://nces.ed.gov/programs/digest/d17/tables/dt17 317.10.asp? current=yes (consultado em 29/01/2019)

${ }^{6} \mathrm{http} / /$ www.youtube.com/watch?feature=player embedded\&v=MqdG4IrITcE\#!, consultado em 17/10/2012.

Ihttp://g1.globo.com/educacao/noticia/2013/04/portugal-sera-excluido-do-ciencia-sem-fronteiras-diz-mercadante.html, consultado pela última vez em 01/10/2013.
} 
O IsF é uma iniciativa em parceria MEC/SESU ${ }^{8}$ e CAPES, que teve seu lançamento oficial - como programa - em dezoito de dezembro de $2012^{9}$, tendo como objetivo central incentivar o aprendizado do idioma inglês por estudantes de instituições de ensino superior do país. De acordo com a portaria que o instituiu, eram seus objetivos:

I - promover, por meio da capacitação na língua inglesa, a formação presencial e virtual de estudantes brasileiros, conferindo-lhes a oportunidade de novas experiências educacionais e profissionais voltadas para a qualidade, o empreendedorismo, a competitividade e a inovação em áreas prioritárias e estratégicas para o Brasil;

II - ampliar a participação e a mobilidade internacional de estudantes de graduação das instituições de educação superior brasileiras, para o desenvolvimento de projetos de pesquisa, estudos, treinamentos e capacitação em instituições de excelência no exterior;

III - contribuir para o processo de internacionalização das instituições de educação superior e dos centros de pesquisa brasileiros;

IV - contribuir para o aperfeiçoamento linguístico do conjunto dos alunos das instituições de educação superior brasileiras; e

V - contribuir para o desenvolvimento dos centros de línguas das instituições de educação superior, ampliando a oferta de vagas. (BRASIL, 2012, p. 28-9)

Em resposta à chamada do Edital SESU 001/2013 para credenciamento de IES federais como Centros Aplicadores TOEFL ITP $^{10}$ e para composição dos Núcleos de Idiomas Inglês Sem Fronteira (NucLi), 43 universidades federais ${ }^{11}$ submeteram projetos e - uma vez que tiveram aprovados seus projetos - montaram seus NucLis; outras 20 se credenciaram como centros aplicadores de TOEFL ITP. A Portaria MEC 1466, de 18 de dezembro de 2012, determinava que as “ [...] ações empreendidas no âmbito do Programa Inglês sem Fronteiras serão complementares às atividades do Programa Ciência sem Fronteiras (BRASIL, 2012, p. 28).

Menos de dois anos depois da instituição do IsF, o MEC publicou em Diário Oficial da União a Portaria No 973, em 14 de novembro de 2014, que ampliou o IsF $^{12}$ para outros idiomas. É possível notar que essa portaria - em relação à que instituiu o IsF - revela

\footnotetext{
${ }_{9}^{8}$ Secretaria de Ensino Superior.

http://www.capes.gov.br/servicos/sala-de-imprensa/36-noticias/5959-lancado-ingles-sem-fronteiras-e-anunciada-nova-formade-pagamento-dos-bolsistas-do-csf, consultado em 29/12/2013.

${ }^{10} \mathrm{O}$ TOEFL (Test of English as a Foreign Language, significando "teste de proficiência em inglês como língua estrangeira") ITP (Institutional Testing Program, significando "programa de testagem institucional") é um exame de proficiência em língua inglesa é aceito por universidades em várias partes do mundo, tendo sido muito utilizado nos programas de mobilidade acadêmica brasileiros (como o Ciência sem Fronteiras). O TOEFL ITP por sua orientação acadêmica, pode ser utilizado por alunos que queiram monitorar sua evolução no idioma e principalmente para quem irá participar de programas de intercâmbio acadêmico.

${ }^{11}$ Apenas IFES com cursos de Licenciatura em Letras Inglês ou Inglês-Português.

${ }^{12}$ Ainda que o MEC tenha tornado o IsF sigla para Idiomas sem Fronteiras, indicando a língua (IsF-Inglês ou IsF-Francês, usarei, neste texto, IsF irrestritamente para Inglês sem Fronteiras e Idiomas sem Fronteiras.
} 
mudanças no discurso oficial. Nota-se uma ampliação no público alvo, agora composto por “[...] estudantes, professores e corpo técnico-administrativo das Instituições de Educação Superior Públicas e Privadas - IES e de professores de idiomas da rede pública de educação básica [...]" (BRASIL, 2014, p. 17). Além disso, os objetivos do programa foram ampliados:

I - promover, por meio da capacitação em diferentes idiomas, a formação presencial e virtual de estudantes, professores e corpo técnico-administrativo das IES e de professores de idiomas da rede pública de educação básica, conferindo-lhes a oportunidade de novas experiências educacionais e profissionais voltadas para a qualidade, o empreendedorismo, a competitividade e a inovação;

II - ampliar a participação e a mobilidade internacional para o desenvolvimento de projetos de pesquisa, estudos, treinamentos e capacitação em instituições de excelência no exterior;

III - contribuir para o processo de internacionalização das IES e dos centros de pesquisa;

IV - contribuir para o aperfeiçoamento linguístico do conjunto dos estudantes das IES;

V - contribuir para a criação, o desenvolvimento e a institucionalização dos centros de línguas nas IES, ampliando a oferta de vagas; e

VI - fortalecer o ensino de idiomas no país, incluindo o da língua portuguesa, e, no exterior, o da língua portuguesa e da cultura brasileira. (BRASIL, 2014, p.17)

Além disso, o entendimento de que o IsF tem o compromisso de contribuir para o ensino de línguas em todo o país - e não só nas IES - é articulado de modo direto. Ademais, o edital estabeleceu o compromisso do programa com o fortalecimento das línguas estrangeiras no Brasil, indicando um comprometimento com a formação dos professores que viria, logo mais, na forma da origem da bolsa, que passa a ser uma bolsa da CAPES de formação de professores.

Como nos ensina o sociólogo da educação Stephen Ball e seus colaboradores (BALL, 1994; BOWE, BALL e GOLD, 1994), as políticas públicas voltadas à educação ganham vida nas práticas sociais dos sujeitos que as vivem no seu cotidiano, e não nos discursos que as instanciam, nem nas esferas públicas de decisão política, tampouco nos textos políticos que as materializam. O epicentro de uma política são os múltiplos cenários da vida cotidiana em que as pessoas conjuntamente (re)constroem-na a partir de seus conceitos, desígnios, agendas, contingências, etc.

É sobre esse entendimento - de que nem sempre os legados de uma política correspondem às intenções de sua formulação - que está assentado o texto aqui apresentado. Neste texto, investigo o legado do IsF a partir das produções acadêmicas que o tem por objeto de estudo, com vistas a responder a seguinte pergunta: (1) quais são as temáticas de 
investigação predominantes? A partir dessa pergunta, argumento, podemos inferir quais estão sendo as maiores áreas de impacto do programa na vida cotidiana.

\section{Metodologia}

Este é um artigo de revisão de literatura; portanto, não pretende adiantar a discussão, mas, sim, verificar em que termos essa discussão tem se dado a partir de bases empíricas. Entre os anos de 2012-2014, não apenas o programa se chamava Inglês sem Fronteiras, como o conhecimento produzido sobre si se deu principalmente na forma de papers apresentados em congressos da área de Letras Brasil afora. Gimenez e Passoni (2016) fizeram uma revisão dos resumos de congressos em que o IsF foi foco dos trabalhos no ano de 2014 e no início do ano de 2015, época em que o IsF ainda engatinhava.

Para este estudo, procedi a uma busca no Google Acadêmico com as palavras "Idiomas sem Fronteiras". Busquei apenas os artigos, teses e dissertações que têm as palavras de busca no título, e encontrei apenas 37 ocorrências $^{14}$-- o que me pareceu bem pouco, pois apenas no mapeamento do site do programa $^{15}$, que não é atualizado desde 2017, há mais de 60 produções. Por isso, ampliei a busca para a opção em que aparecem quaisquer textos que tenham as palavras-chave em qualquer lugar do texto. A diferença foi considerável: 475 resultados.

Desse modo, optei por analisar os resultados, ano a ano, isto é, entre 2015 e $2019^{16}$. Em 2015, 57 textos respondem à pesquisa com as já referidas palavras-chave. Em 2016, 114 aparecem após realizar pesquisa com as mesmas palavras-chave. Em 2017, o número sobe um pouco, para 125 resultados, e permanece estável - 127 resultados - no ano de 2018 . No ano de 2019, como não é de se estranhar já que ano está começando, apenas 15 textos correspondem aos parâmetros de busca estabelecidos.

Visto que o número de textos é demais para o escopo deste texto, formulei o seguinte método para restringir um pouco o universo amostral de artigos, dissertações e teses para análise. Decidi tratar de 5 textos no ano de 2015 e 10 por ano, nos anos de 2016, 2017 e 2018.

\footnotetext{
${ }^{13}$ https://scholar.google.com.br

14 Todas as buscas aqui relatadas foram realizadas pela última vez em 21/03/2019.

15 http://isf.mec.gov.br/pesquisas-e-relatorios

${ }^{16}$ Buscando as mesmas palavra-chave entre 2011 e 2014, apenas cinco textos aparecem, sendo que em todos, exceto um caso, o IsF é apenas uma menção em relatórios de pesquisa sobre outros temas.
} 
Para tanto, ativei a função "classificar por relevância" do Google Acadêmico, que classifica os textos de acordo com o número de citações e com o número de clicks.

Por fim, procedi à leitura de um a um dos textos - artigos, teses e dissertações, e capítulos de livros - e notei que alguns não tratavam do programa, mas o mencionavam por algum motivo. Desse modo, optei por excluir esses textos. Ademais, excluí o livro organizado pela executiva do programa no MEC e patrocinado com verba do ministério, visto que não é um trabalho acadêmico comum, e, sim, um compilado de trabalhos acadêmicos de pesquisadores diretamente envolvidos com o programa em suas universidades e, até onde me consta, não tenha havido revisão cega por pares. Ainda que no caso das teses e dissertações também não haja avaliação cega, os trabalhos passam pelo crivo da banca.

A seguir, apresento e discuto os quadros sinóticos com os resultados ano a ano.

\section{Resultados}

Em 2014 saíram à luz do dia os primeiros trabalhos a enfocar os resultados do IsF nas universidades, na forma de trabalhos apresentados em congressos realizados no Brasil, dos quais temos acesso pelos resumos de ditos congressos, ou, em alguns casos, pela memória dos participantes. O primeiro desses trabalhos de que tenho notícia (SARMENTO e KIRSCH, 2014), ainda quando o programa IsF ainda se referia apenas à língua inglesa e ainda se pretendia um programa acessório ao $\mathrm{CsF}$, já apontava formação de professores como um possível ganho do programa, a partir de observação participante de um NucLi de uma grande universidade do sul do Brasil. De certo modo, esse entendimento de que o programa, localmente era reinterpretado pelos participantes, e, assim, poderia ser reconfigurado em um programa de formação de professores parece ter dados as tintas e oferecido os termos a muito dos trabalhos que viriam depois.

Gimenez e Passoni (2016) fazem uma revisão bibliográfica dos resumos de trabalhos que tinham o IsF por foco apresentados em congressos entre 2014 e 2015 - mais especificamente o V Congresso Latino Americano de Formação de Professores de Línguas (CLAFPL), a IV Congresso da Associação Brasileira Professores Universitários de Inglês (ABRAPUI) e o XI Congresso Brasileiro de Linguística Aplicada (CBLA). De acordo com as autoras, o tema da formação de professores é predominante nessa primeira leva de trabalhos que foram publicados quando o IsF ainda era incipiente. Além disso, a maioria dos trabalhos 
eram fruto de investigação participante de pessoas envolvidas com o programa em suas universidades, isto é, professores bolsistas e coordenadores. É interessante notar que os eventos de 2014, tanto o CLAFPL como a ABRAPUI, antecedem a publicação da portaria No 973 - citada na introdução deste texto -, em que o IsF se compromete com a melhoria do ensino de língua inglesa no país. Ademais, em janeiro de 2015 o IsF publica a portaria de No 30, em que o programa se compromete com oferecer cursos de línguas a professores e professoras da educação básica. Em outras palavras, essa temporalidade pode sugerir que as inteligibilidades produzidas pelos referidos trabalhos de algum modo tenham sido levadas em conta na condução do programa; nesse sentido, seria como afirmar que o ciclo de políticas de Ball e colaboradores (BALL, 1994; BOWE, BALL e GOLD, 1994) teve seu ciclo completo no Idiomas sem Fronteiras, isto é, da produção da política ao contexto de prática e de volta ao contexto de produção da política.

Em 2015, passam a aparecer os primeiros artigos revisados por pares com o IsF como foco, tanto de modo direto como de modo indireto; além disso, também foram publicados artigos em livros, dissertações e teses. O quadro abaixo resume os resultados da busca pelos textos do ano de 2015 .

\begin{tabular}{|c|c|c|}
\hline Título, autor e revista/programa & Tema(s) & Gênero \\
\hline $\begin{array}{l}\text { Archanjo, R. (2015). Globalização e Multilingualismo } \\
\text { no Brasil Competência Linguística e o Programa } \\
\text { Ciência Sem Fronteiras. Revista Brasileira de } \\
\text { Linguística Aplicada, 15(3), 621-656. }\end{array}$ & $\begin{array}{l}\text { Globalização; } \\
\text { multilingualismo; } \\
\text { políticas linguísticas; } \\
\text { ensino e } \\
\text { aprendizagem de } \\
\text { língua estrangeira }\end{array}$ & $\begin{array}{l}\text { Artigo em } \\
\text { periódico }\end{array}$ \\
\hline $\begin{array}{l}\text { Dorigon, T. (2015). O Programa Idiomas sem } \\
\text { Fronteiras Analisado a partir do Ciclo de Políticas. } \\
\text { BELT, 6, 4-20. }\end{array}$ & $\begin{array}{l}\text { Políticas } \\
\text { Linguísticas }\end{array}$ & $\begin{array}{l}\text { Artigo em } \\
\text { periódico }\end{array}$ \\
\hline $\begin{array}{l}\text { Lamberts, D. (2015). O livro didatico de lingua inglesa } \\
\text { em uso: analise de pesquisas e observações de aula no } \\
\text { programa Idiomas sem Fronteiras. Dissertação de } \\
\text { mestrado, PPGLET UFRGS, Porto Alegre. }\end{array}$ & Uso do livro didático & $\begin{array}{l}\text { Dissertação de } \\
\text { mestrado }\end{array}$ \\
\hline $\begin{array}{l}\text { Sarmento \& Kirsch. (2015). Inglês sem fronteiras: } \\
\text { Uma mirada ao contexto de prática pelo prisma da } \\
\text { formação de professores. Ilha Do Desterro, v.1, n. } 68 \text {, } \\
\text { p. } 47-59,2015 \text {. }\end{array}$ & $\begin{array}{l}\text { Formação de } \\
\text { professores }\end{array}$ & $\begin{array}{l}\text { Artigo em } \\
\text { periódico }\end{array}$ \\
\hline $\begin{array}{l}\text { Haus, C. (2015). O Ensino-Aprendizagem da } \\
\text { Pronúncia no Programa Inglês sem Fronteiras (IsF) na } \\
\text { Universidade Federal do Paraná (UFPR): análise da } \\
\text { perspectiva dos professores, } 6,62-75 \text {. }\end{array}$ & $\begin{array}{l}\text { Ensino de pronúncia; } \\
\text { formação de } \\
\text { professores }\end{array}$ & $\begin{array}{l}\text { Artigo em } \\
\text { periódico }\end{array}$ \\
\hline
\end{tabular}

Quadro 1: produções do ano de 2015

Como já dito anteriormente, a busca relativa ao ano de 2015 no Google Acadêmico aponta 57 trabalhos, dos quais apresento cinco aqui. Como podemos ver no quadro acima, há 
uma distribuição equânime de temáticas de pesquisa - política linguística, internacionalização, formação de professores e uso do livro didático. Desses, os mais preponderantes são os de política linguística e de formação de professores, ainda que em nem todas ocorrências as temáticas apareçam em versão puro-sangue, isto é, entrecruzam-se umas com as outras. A maioria dos trabalhos, como podemos ver, é composta por artigos em periódicos, sendo que já há uma dissertação de mestrado estudando o programa.

A seguir, apresento o quadro sinótico obtido com as buscas relacionadas ao ano de 2016. Como já dito, no ano de 2016 as produções que responde à pesquisa pelas palavras-chave ISF aumenta significativamente - indo de 57, no ano, anterior a 114.

\begin{tabular}{|c|c|c|}
\hline Título, autor e revista/programa & Tema & Gênero \\
\hline $\begin{array}{l}\text { Archanjo, R. (2016). Saberes sem Fronteiras: } \\
\text { Políticas para as migraçóes Pós-modernas. DELTA, } \\
32(2), 515-542 \text {. }\end{array}$ & Política Linguística & $\begin{array}{l}\text { Artigo } \\
\text { periódico }\end{array}$ \\
\hline $\begin{array}{l}\text { Gimenez, T., \& Passoni, T. P. (2016). Políticas } \\
\text { linguísticas e suas consequências não planejadas: o } \\
\text { programa "Inglês Sem Fronteiras" e suas } \\
\text { repercussões nos cursos de Letras. Calidoscópio, } \\
14(1), 115-126 .\end{array}$ & $\begin{array}{l}\text { Política Linguística; } \\
\text { formação de de } \\
\text { professores }\end{array}$ & $\begin{array}{l}\text { Artigo } \\
\text { periódico }\end{array}$ \\
\hline $\begin{array}{l}\text { Finardi, K., Santos, J., \& Guimarães, F. (2016). A } \\
\text { relação entre línguas estrangeiras e o processo de } \\
\text { internacionalização : evidências da Coordenação de } \\
\text { Letramento Internacional de uma Universidade } \\
\text { Federal. Interfaces Brasil/Canadá, 16(1), 233-255. }\end{array}$ & $\begin{array}{l}\text { Internacionalização } \\
\text { universitária }\end{array}$ & $\begin{array}{l}\text { Artigo } \\
\text { periódico }\end{array}$ \\
\hline $\begin{array}{l}\text { Jorge, M. (2016). Línguas Estrangeiras em } \\
\text { Evidência : Formação de Professores, Justiça Social } \\
\text { e Letramentos. }\end{array}$ & $\begin{array}{l}\text { Formação de } \\
\text { professores; } \\
\text { letramento em língua } \\
\text { adicional }\end{array}$ & $\begin{array}{l}\text { Artigo } \\
\text { periódico }\end{array}$ \\
\hline $\begin{array}{l}\text { Della Rosa, F., Kawachi-furlan, C. J., \& Augusto- } \\
\text { navarro, E. H. (2016). Inglês para propósitos } \\
\text { especificos (IPE): características e tendências atuais } \\
\text { de ensino. EntreLínguas, 2(1), 25-39. }\end{array}$ & $\begin{array}{l}\text { Inglês para fins } \\
\text { específicos; ensino } \\
\text { de inglês }\end{array}$ & $\begin{array}{l}\text { Artigo } \\
\text { periódico }\end{array}$ \\
\hline $\begin{array}{l}\text { Galli, J. A. (2016). Letramento em línguas } \\
\text { estrangeiras no brasil : o projeto brafitec e sua relação } \\
\text { FOS/FOU. Revista Do Gelne, } 18(2), 184-203 \text {. }\end{array}$ & $\begin{array}{l}\text { Letramento em } \\
\text { língua adicional }\end{array}$ & $\begin{array}{l}\text { Artigo } \\
\text { periódico }\end{array}$ \\
\hline
\end{tabular}

Quadro 2: produções do ano de 2016

Novamente, o gênero predominante é o de artigo em periódico. Além disso, como podemos ver no quadro sinótico, há outra vez uma distribuição equânime entre as diferentes temáticas propostas - formação de professores, política linguística, internacionalização, 
inglês como língua adicional e inglês para fins específicos. Outra vez, política linguística e formação de professores são as temáticas mais preponderantes, o que demonstra que se mantém a tendência do ano anterior. A seguir, apresento os resultados de 2017, que, como já disse, apresenta um leve aumento no quantitativo de produções encontradas no Google Acadêmico - de 114 para 117 . 


\begin{tabular}{|c|c|c|}
\hline Título, autor e revista/programa & Tema & Gênero \\
\hline $\begin{array}{l}\text { Amorim, G. B., \& Finardi, K. R. (2017). } \\
\text { Internacionalização do ensino superior e linguas } \\
\text { estrangeiras : evidências de um estudo de caso nos } \\
\text { niveis micro, meso e macro. Avaliação, 22(03), 614- } \\
632 \text {. }\end{array}$ & $\begin{array}{l}\text { Internacionalização } \\
\text { universitária }\end{array}$ & $\begin{array}{l}\text { Artigo em } \\
\text { periódico }\end{array}$ \\
\hline $\begin{array}{l}\text { Kirsch. (2017). Teacher development in a community } \\
\text { of practice in southern Brazil. }\end{array}$ & $\begin{array}{l}\text { Formação de } \\
\text { professores }\end{array}$ & Tese de doutorado \\
\hline $\begin{array}{l}\text { Vasconcelos, C. N., Costa, D., \& Silva, F. (2017). } \\
\text { Idiomas sem Fronteiras no Brasil. In Encontros } \\
\text { Universitários da UFC } 2017 \text { (p. 5250). }\end{array}$ & Sinópse do programa & Resumo em anais \\
\hline $\begin{array}{l}\text { Matte, M. L. (2017). Ensino de inglês acadêmico na } \\
\text { perspectiva dos professores- bolsistas do Programa } \\
\text { Idiomas sem Fronteiras. In Salão de Iniciação } \\
\text { Cientifica. }\end{array}$ & $\begin{array}{l}\text { Inglês para fins } \\
\text { especificos; } \\
\text { formação de } \\
\text { professores }\end{array}$ & Resumo em anais \\
\hline $\begin{array}{l}\text { Fonseca, A., \& Ferreira, F. A. C. (2017). World } \\
\text { Englishes : a interação entre alunos dos programas } \\
\text { Português para Estrangeiros e Idiomas sem Fronteiras } \\
\text { em sala de aula. In Salão UFRGS 2017: XIII SALÃO } \\
\text { DE ENSINO DA UFRGS. }\end{array}$ & $\begin{array}{l}\text { Interação em sala de } \\
\text { aula }\end{array}$ & Resumo em anais \\
\hline $\begin{array}{l}\text { Pereira, F. M. (2017). O Programa Idiomas sem } \\
\text { Fronteiras e a formação de professores de inglês na } \\
\text { UFBA : objetivos (inter) nacionais em práticas locais } \\
\text { Revistas Letras Raras, } 6(1), 151-165 \text {. }\end{array}$ & $\begin{array}{l}\text { Formação de } \\
\text { professores }\end{array}$ & $\begin{array}{l}\text { Artigo em } \\
\text { periódico }\end{array}$ \\
\hline $\begin{array}{l}\text { Freitas, P. G. De, Veloso, F. S., Perry, E. C., \& } \\
\text { Mastroberardino, R. E. (2017). A implementação do } \\
\text { ensino de lingua italiana no programa Idiomas sem } \\
\text { Fronteiras na Universidade Federal do Paraná : } \\
\text { conquistas e desafios. Letras Raras, } 6(1), 20-37 \text {. }\end{array}$ & $\begin{array}{l}\text { Gestão universitária } \\
\text { e implementação de } \\
\text { programa }\end{array}$ & $\begin{array}{l}\text { Artigo em } \\
\text { periódico }\end{array}$ \\
\hline $\begin{array}{l}\text { Baffi-bonvino, M. A., Casanova, G. D., \& Zorzeto, M. } \\
\text { S. (2017). Reflexões acerca da proficiência em lingua } \\
\text { inglesa por professores em formação: impacto e efeito } \\
\text { retroativo do Programa Idiomas sem Fronteiras. Letras } \\
\text { Raras, } 6(1), 128-150 \text {. }\end{array}$ & $\begin{array}{l}\text { Proficiência em } \\
\text { língua adicional; } \\
\text { formação de } \\
\text { professores }\end{array}$ & $\begin{array}{l}\text { Artigo em } \\
\text { periódico }\end{array}$ \\
\hline $\begin{array}{l}\text { Fonseca, J. G. da, \& Ximenes, J. C. (2017). O } \\
\text { Programa Idiomas Sem Fronteiras - ISF e a formação } \\
\text { do professor de Lingua Alemã da Universidade } \\
\text { Federal da Bahia. Letras Raras, } 6(1), 7-19 \text {. }\end{array}$ & $\begin{array}{l}\text { Formação de } \\
\text { professores }\end{array}$ & $\begin{array}{l}\text { Artigo em } \\
\text { periódico }\end{array}$ \\
\hline
\end{tabular}

Quadro 3: produções do ano de 2017

Como podemos ver, voltamos a ter uma predominância de artigos em periódico, mas, desta vez, menos intensa que nos anos anteriores, visto que também temos uma tese de doutorado e três resumos em anais. Outra vez formação de professores aparece na cabeceira em relação ao número de produções, sendo que nesse ano de forma mais marcada, correspondendo a cinco ocorrências.

Por fim, apresento o resultado do ano de 2018. Como já apontado, é um ano em que o número de produções se mantém relativamente estável em comparação ao ano anterior - 127 resultados. 


\begin{tabular}{|c|c|c|}
\hline Título, autor e revista/programa & Tema & Gênero \\
\hline $\begin{array}{l}\text { Rodrigues, Y. S., Honório, A. P. P., Simão, K. Y. B., } \\
\text { \& Silva, D. C. F. (2018). Técnicas de correção de } \\
\text { aspectos suprasegmentais da lingua inglesa no } \\
\text { programa Idiomas sem Fronteiras. In XII Encontro } \\
\text { de Práticas Docentes / VI Seminário Institucional de } \\
\text { Iniciação à Docência (p. 6210). }\end{array}$ & Feedback corretivo & $\begin{array}{l}\text { Resumo em anais; } \\
\text { pôster }\end{array}$ \\
\hline $\begin{array}{l}\text { Arago, A. F. S., Honorio, A. P. P., \& Silva, D. C. F. } \\
\text { (2018). Análise dos principais erros gramaticais } \\
\text { identificados em parágrafos escritos em lingua } \\
\text { inglesa por alunos do programa Idiomas sem } \\
\text { Fronteiras. In XII Encontro de Práticas Docentes / VI } \\
\text { Seminário Institucional de Iniciação à Docência (p. } \\
6166 \text { ). }\end{array}$ & Feedback corretivo & $\begin{array}{l}\text { Resumo em anais; } \\
\text { pôster }\end{array}$ \\
\hline $\begin{array}{l}\text { Veloso, F. S., \& Freitas, P. G. (2018). A implantação } \\
\text { do ensino de lingua italiana no programa Idiomas } \\
\text { sem Fronteiras na Universidade Federal do Paraná : } \\
\text { conquistas e desafios. In Actas do XIII Congreso } \\
\text { Internacional de Linguística Xeral (pp. 817-821). } \\
\text { Vigo. }\end{array}$ & $\begin{array}{l}\text { Gestão universitária e } \\
\text { implementação de } \\
\text { programa }\end{array}$ & $\begin{array}{l}\text { Artigo em } \\
\text { periódico }\end{array}$ \\
\hline $\begin{array}{l}\text { Mozer, I. P., \& Kawachi-Furlan, C. J. (2017). Not by } \\
\text { the book : the experience of designing teaching } \\
\text { material for an English for Specific Purposes course } \\
\text { in the Program Languages without Borders. A Cor } \\
\text { Das Letras, 18(Especial), 145-162. }\end{array}$ & $\begin{array}{l}\text { Formação de } \\
\text { professores }\end{array}$ & $\begin{array}{l}\text { Artigo em } \\
\text { periódico }\end{array}$ \\
\hline $\begin{array}{l}\text { Medeiros, I. M. de O., \& Furtado, R. N. M. (2018). } \\
\text { Reflexões sobre o ensino voltado para leitura de } \\
\text { textos acadêmicos, para estrangeiros, do programa } \\
\text { Idiomas sem Fronteiras, da UFC. In XII Encontro de } \\
\text { Práticas Docentes / VI Seminário Institucional de } \\
\text { Iniciação à Docência (p. 6206). }\end{array}$ & $\begin{array}{l}\text { Ensino e } \\
\text { aprendizagem de } \\
\text { lingua adicional }\end{array}$ & $\begin{array}{l}\text { Resumo em anais; } \\
\text { pôster }\end{array}$ \\
\hline $\begin{array}{l}\text { Morin, G. P. (2018). Idiomas sem } \\
\text { Fronteiras/Espanhol: criação de um curso no elo para } \\
\text { complementar as aulas presenciais. UFSM. }\end{array}$ & $\begin{array}{l}\text { Produção de material } \\
\text { didático }\end{array}$ & $\begin{array}{l}\text { Monografia de } \\
\text { especialização }\end{array}$ \\
\hline $\begin{array}{l}\text { Mota, A. C. D. da, \& Diana Costa Fortier Silva. } \\
\text { (2018). Relato de experiência dos alunos do curso de } \\
\text { produção oral: debates do programa Idiomas sem } \\
\text { Fronteiras. In XII Encontro de Práticas Docentes / VI } \\
\text { Seminário Institucional de Iniciação à Docência } \\
\text { (Vo1. 10, p. 6208). }\end{array}$ & $\begin{array}{l}\text { Ensino e } \\
\text { aprendizagem }\end{array}$ & \\
\hline $\begin{array}{l}\text { Pereira, F. (2018). Ensino de inglês no PROFICI e } \\
\text { no NucLi UFBA (Programa Idiomas sem Fronteiras) } \\
\text { em tempos de pós-método e internacionalização: } \\
\text { convergências e especificidades. Revista Leitura, } \\
61(2), 59-75 \text {. }\end{array}$ & $\begin{array}{l}\text { Metodologia de } \\
\text { ensino; } \\
\text { internacionalização }\end{array}$ & $\begin{array}{l}\text { Artigo em } \\
\text { periódico }\end{array}$ \\
\hline
\end{tabular}

Quadro 4: produções do ano de 2018

No último ano analisado, há alguns câmbios interessantes em relação aos anos anteriores. Em primeiro lugar, há uma variedade maior de gêneros dos discursos em relação a como os relatórios de pesquisa são apresentados, sendo o resumo em anais o mais frequente, diferentemente dos anos anteriores. Além disso, há uma maior variedade de temáticas, sendo feedback corretivo o mais frequente. Formação de professores, dessa vez, aprece apenas uma vez; o mesmo ocorre com internacionalização. Como um dos critérios de atribuição de relevância do Google Acadêmico é o número de citações, e o ano de 2018 recém acabara na 
data dessa pesquisa - muitos dos trabalhos que citariam produções do ano de 2018 ainda não tiveram tempo o suficiente para serem publicados -, é possível afirmar que os resultados de 2018 ainda sejam de pouca credibilidade. Dito de outro modo, é provável que com o passar do tempo outras produções, que não os resumos em anais, sejam mais citadas e subam para a cabeceira da relevância atribuída, mas isso não deixa de ser especulação futurológica.

Na próxima sessão, teço alguns comentários sobre os resultados obtidos aqui.

\section{Comentários finais}

Ao analisar os dados, algumas coisas imediatamente saltam à vista. Em primeiro lugar, o conceito de internacionalização não aparece nas primeiras portarias do programa, mas surge nos primeiros relatórios de pesquisa que endereçam o IsF. Dito de outro modo, o programa foi batizado como um programa de internacionalização pelas produções que o enfocavam e, só depois, tal conceito passa a figurar nos documentos oficiais do programa.

Além disso, parece que a formação de professores foi uma agenda advinda primeiramente do contexto de prática do IsF, visto que nas primeiras portarias a propor e regulamentar o programa a formação de professores não está no horizonte. Entretanto, a partir do ano de 2015 o IsF passa a ser tratado como um programa focado na formação de professores, sendo que a bolsa passa a ser uma bolsa CAPES de formação de professores. Efetivamente, o tema mais frequentemente enfocado pelas produções relativas ao programa neste pequeno corpus compilado aqui é a questão da formação de professores, vista de uma série de ângulos diferentes, mas, sobretudo, desde o ponto de vista do contexto especifico dos diferentes NucLis espalhados pelo país e dos participantes desses NucLis. Diversas vezes, inclusive, o pesquisador é um atual ou egresso coordenador ou professor bolsista do programa.

Por fim, é possível entender que há um telos nas produções que tratam do programa. No princípio, as produções que enfocavam o IsF eram principalmente apresentações em congressos e eventos; em seguida, o gênero mais frequente passou a ser o de artigos em periódicos; então, surgiram monografias, dissertações e teses enfocando o programa. É curioso, porém, que as produções mais relevantes do último ano do corpus voltam a ser as apresentações em eventos, na forma de resumos online. Que isso implica? É difícil responder, mas duas interpretações pululam. A primeira é de que precisamos esperar um pouco mais para 
que, novamente, artigos, dissertações e teses passem a ocupar a cabeceira da relevância nas pesquisas relativas a esse ano também; a segunda é a de que o programa pode ter cumprido um ciclo de forte interesse do ponto de vista da produção de conhecimento acadêmico, interesse esse que, estaria arrefecendo. Eu particularmente estou curioso para saber se alguma delas estará correta.

Por fim, é interessante perceber que nossos desígnios e cosmovisões podem penetrar uma política de estado, mesmo essas estando sempre, aparentemente, tão distantes de nós. Isso indica que o nosso exercício de produção de conhecimento e militância política para que esse conhecimento seja reconhecível nas esferas que decidem sobre a vida da população nem sempre são em vão. Também estou curioso para ver o que o futuro nos reserva nesse quesito.

\section{REFERÊNCIAS}

AMORIM, Gabriel B.; FINARDI, Kyria R. Internacionalização do ensino superior e línguas estrangeiras: evidências de um estudo de caso nos níveis micro, meso e macro. Avaliação, v. 03, n. 22, p.614-632, 2017.

ARAGO, Ângelo. F. S.; HONORIO, Arthur P. P.; SILVA, Diana C. F. Análise dos principais erros gramaticais identificados em parágrafos escritos em língua inglesa por alunos do programa Idiomas sem Fronteiras. In XII Encontro de Práticas Docentes / VI Seminário Institucional de Iniciação à Docência, p. 6166, 2018.

ARCHANJO, Renata. Globalização e Multilingualismo no Brasil Competência Linguística e o Programa Ciência Sem Fronteiras. Revista Brasileira de Linguística Aplicada, v. 3, n.15, p. 621-656, 2015.

ARCHANJO, Renata. Saberes sem Fronteiras: Políticas para as migrações Pós-modernas. DELTA, v. 2, n. 32, p. 515-542, 2016.

BAFFI-BONVINO, Melissa A.; CASANOVA, Giovana D.; Zorzeto, Mariana S. (2017). Reflexões acerca da proficiência em língua inglesa por professores em formação: impacto e efeito retroativo do Programa Idiomas sem Fronteiras. Letras Raras, v.1, n. 6, p.128-150, 2017.

BALL, Stephen J. Education reform: a critical and post structural approach. Buckingham: Open University Press, 1994.

BOWE, R.; BALL, S.J.; GOLD, A. Reforming Education \& Changing Schools: case studies in policy sociology. London, Routledge, 192 p., 1992. 
BRASIL. 2012. Ministério da Educação. Portaria No 1.466, de 18 de dezembro de 2012. Disponível em: http://isf.mec.gov.br/ingles/images/ pdf/portaria_normativa_1466_2012.pdf Acesso em 29 de nov. de 2016.

BRASIL. 2014. Ministério da Educação. Portaria No 973, de 14 de novembro de 2014. Disponível em: http://isf.mec.gov.br/ingles/ images/pdf/novembro/Portaria_973_Idiomas_sem_Fronteiras.pdf Acesso em: 29 de fev. de 2016 .

BRASIL. 2016. Ministério da Educação. Portaria No 30, de 26 de janeiro de 2016. Disponível em http://isf.mec.gov.br/ingles/images/2016/ janeiro/Portaria_n_30_de_26_de_janeiro_de_2016_DOU.pdf Acesso em: 29 de fev. de 2016.

DELLA ROSA, Fernanda; KAWACHI-FURLAN, Cláudia J.; AUGUSTO-NAVARRO, Eliane H. Inglês para propósitos específicos (IPE): características e tendências atuais de ensino. EntreLinguas, v. 2, n. 1, p. 25-39, 2016.

DORIGON, T. (2015). O Programa Idiomas sem Fronteiras Analisado a partir do Ciclo de Políticas. BELT, volume especial, n. 6, p. 4-20, 2015.

FINARDI, Kyria; SANTOS, Jane; GUIMARÃES, Felipe. A relação entre línguas estrangeiras e o processo de internacionalização: evidências da Coordenação de Letramento Internacional de uma Universidade Federal. Interfaces Brasil/Canadá, v. 1, n. 16, p. 233-255, 2016.

FONSECA, André; FERREIRA, Felipe A. C. World Englishes : a interação entre alunos dos programas Português para Estrangeiros e Idiomas sem Fronteiras em sala de aula. In Salão UFRGS 2017 : XIII SALÃO DE ENSINO DA UFRGS, 2017.

FONSECA, Jael G. ; XIMENES, Joel C. O Programa Idiomas Sem Fronteiras - ISF e a formação do professor de Língua Alemã da Universidade Federal da Bahia. Letras Raras, v.1, n. 6, p. 7-19, 2017.

FREITAS, Paula G.; Veloso, Fernanda S.; Perry, Eliane C.; Mastroberardino, Ranieri E. (2017). A implementação do ensino de língua italiana no programa Idiomas sem Fronteiras na Universidade Federal do Paraná: conquistas e desafios. Letras Raras, v.1, n. 6, p. 20-37, 2017.

GALLI, J. A. Letramento em línguas estrangeiras no Brasil: o projeto Brafitec e sua relação FOS/FOU. Revista Do Gelne, v. 2, n. 18, p. 184-203, 2016.

GIMENEZ, Telma; PASSONI, Thais P. Políticas linguísticas e suas consequências não planejadas: o programa "Inglês Sem Fronteiras" e suas repercussões nos cursos de Letras. Calidoscópio, v. 1, n.14, p. 115-126, 2016. 
HAUS, Camila. O Ensino-Aprendizagem da Pronúncia no Programa Inglês sem Fronteiras (IsF) na Universidade Federal do Paraná (UFPR): análise da perspectiva dos professores. BELT, v. 6, Número Especial, p. 62-75, 2015.

JORGE, Mirian. (2016). Línguas Estrangeiras em Evidência: Formação de Professores, Justiça Social e Letramentos. In FERREIRA, Maria C. D.; Reichmann, C. L.; Romero, T. S. (Orgs.). Campinas, Pontes, 2016, p. 121-137.

KIRSCH, William. Teacher development in a community of practice in southern Brazil. Tese de doutorado, PPGLET UFRGS, 2017.

KIRSCH, W.; SARMENTO, S. (2018). Workshops as an avenue of teacher development in a Language without Borders community in Southern Brazil. BELT, v. 9, n. 2, p. 395-408, 2018.

LAMBERTS, Denise. O livro didático de língua inglesa em uso: analise de pesquisas e observações de aula no programa Idiomas sem Fronteiras. Dissertação de mestrado, PPGLET UFRGS, Porto Alegre, 2015.

MATTE, Marine L. (2017). Ensino de inglês acadêmico na perspectiva dos professoresbolsistas do Programa Idiomas sem Fronteiras. In Salão de Iniciação Científica UFRGS, 2017. Disponível

em: https://www.lume.ufrgs.br/bitstream/handle/10183/176283/Poster_53366.pdf? sequence=2

MEDEIROS, Igor M. de O.; FURTADO, Raimundo N. M. Reflexões sobre o ensino voltado para leitura de textos acadêmicos, para estrangeiros, do programa Idiomas sem Fronteiras, da UFC. In XII Encontro de Práticas Docentes / VI Seminário Institucional de Iniciação à Docência (p. 6206), 2018.

MORIN, Gabriela P. (2018). Idiomas sem Fronteiras/Espanhol: criação de um curso no elo para complementar as aulas presenciais. Monografia de especialização de Especialização em Tecnologias da Informação e da Comunicação Aplicadas à Educação, UFSM, 2018.

MOTA, Albert C. D.; SILVA, Diana C. F. Relato de experiência dos alunos do curso de produção oral: debates do programa Idiomas sem Fronteiras. In XII Encontro de Práticas Docentes / VI Seminário Institucional de Iniciação à Docência, p. 6208), 2018.

MOZER, Isadora P.; KAWACHI-FURLAN, Claudia J. Not by the book : the experience of designing teaching material for an English for Specific Purposes course in the Program Languages without Borders. A Cor Das Letras, n. 18, p. 145-162, 2017.

PEREIRA, Fernanda. Ensino de inglês no PROFICI e no NucLi UFBA (Programa Idiomas sem Fronteiras) em tempos de pós-método e internacionalização: convergências e especificidades. Revista Leitura, v. 2, n. 61, p. 59-75, 2018. 
PEREIRA, Fernanda M. O Programa Idiomas sem Fronteiras e a formação de professores de inglês na UFBA : objetivos (inter) nacionais em práticas locais. Revistas Letras Raras, v.1, n. 6, p. 151-165, 2017.

RODRIGUES, Yasmin S.; HONÓRIO, Arthur P. P.; SIMÃO, KARLA Y. B.; SILVA, DIANA C. F. Técnicas de correção de aspectos suprasegmentais da língua inglesa no programa Idiomas sem Fronteiras. In XII Encontro de Práticas Docentes / VI Seminário Institucional de Iniciação à Docência, p. 6210, 2018.

SARMENTO, Simone; KIRSCH, William. Inglês sem fronteiras: Uma mirada ao contexto de prática pelo prisma da formação de professores. Ilha Do Desterro, v.1, n. 68, p. 47-59, 2015.

VASCONCELOS, Cid N.; SILVA, Diana C. F. Idiomas sem Fronteiras no Brasil. In Encontros Universitários da UFC 2017, p. 5250, 2017.

VELOSO, FERNANDA S.; FREITAS, Paula G. A implantação do ensino de língua italiana no programa Idiomas sem Fronteiras na Universidade Federal do Paraná: conquistas e desafios. In Actas do XIII Congreso Internacional de Lingüística Xeral, p. 817-821, 2018. 